\title{
Biplanar Fixation by (Extra-Focal) Screw in Medial Wedge Opening High Tibial Osteotomy (MWOHTO)
}

\author{
Ahmed A Khalifa ${ }^{1 *}$, Amr A Fadle ${ }^{2}$, Mohammad Ali Alzohiry ${ }^{3}$, Mohamed Eslam Elsherif ${ }^{3}$ and Omar Refai ${ }^{2,3}$ \\ ${ }^{1}$ Orthopaedic Department, Qena Faculty of medicine and its university hospital, Qena, Egypt \\ ${ }^{2}$ Orthopaedic Department, Assiut university hospital, Assiut, Egypt \\ ${ }^{3}$ Orthopaedic Department, Al-Rehab 2 specialized hospital, Assiut, Egypt
}

Submission: December 26, 2019; Published: January 21, 2020

*Corresponding author: Ahmed A Khalifa, Assistant Professor of Orthopaedic surgery-Arthroplasty consultant, Qena faculty of medicine and university hospital, South Valley university, Egypt

\begin{abstract}
Introduction: Medial wedge opening high tibial osteotomy (MWOHTO) is effective for a variety of knee conditions, knee osteoarthritis with varus malalignment and proximal tibial deformity without arthritic changes are among the indications. Although it is a highly successful, complications such as non-union, delayed union and fixation failure are still occurring. In this study, we are describing the results of using an extra focal screw fixation while performing (MWOHTO) as a new technique to obtain extra stability at the osteotomy site.
\end{abstract}

Material and Methods: 50 patients had been operated started at November 2018 with minimum follow up of 6 months, 32 females and 18 males, mean age 48.5 yrs., 44 patients with medial OA with varus deformity and 6 patients tibia vara, in all patients, osteotomy was fixed using a T locked titanium plate supplemented by extra focal screw. Radiographs and time to full weight-bearing were assessed.

Results: Post-operative Knee range of motion was not significantly changed from pre-operative values. Anatomical TF angle improved significantly from 177.1 to 187.5 ( $\mathrm{p}<0.01$ ), (MPTA) improved significantly from 83.5 to 94.2 ( $\mathrm{p}<0,01$ ). The average union time was 7.9 weeks \pm 2.8. The average time for full weight-bearing was 8.9 weeks. $24 \%$ minor complication, 4 patients under-corrected, 2 over-corrected and three patients with delayed union.

Conclusion and Recommendations: Biplanar fixation by adding an extra focal screw in MWOHTO adds to the stability of the osteotomy by resisting torsional forces thus, decreasing the incidence of non-union and improving early recovery, the further biomechanical study is highly recommended

Keywords: High tibial osteotomy; fixation; extra-focal screw; Biplanar

\section{Introduction}

High tibial osteotomy was introduced by Jackson et al. in 1911 and was popularized by Coventry in 1985 as an effective treatment for a variety of knee conditions including knee osteoarthritis with varus deformity and tibia vara without arthritis [1-3]. The aim of medial wedge opening high tibial osteotomy (MWOHTO) is to relieve pain and delay the progression of the degenerative process by offloading medial knee compartment and correcting malalignment using different fixation methods (Stables, T-plate, Budu plate, and TomoFix) [4]. Although highly successful procedure, complications like implant failure, non-union and delayed union are still frequently occurring with a reported incidence of $5.7 \%$ despite good patient selection, proper operative technique and using stiffer implants [5-10]. In this study, we discuss our results after utilizing a new technique by adding an extra screw in another plane away from the primary fixation (extra-focal) and its effect on union and time to full weightbearing, reporting any complications related to this technique. Our hypothesis is that adding this extra focal screw will add more stability to the osteotomy fixation with subsequent reduction of the complications related to osteotomy fixation and union.

\section{Materials and Methods}

Starting from November 2018, fifty patients (50 knees) were treated by this technique, 32 (64\%) females and 18 (36\%) males 
with a mean age of $48.5 \pm 7.4$ years, 44 (88\%) patients diagnosed with primary medial unicompartmental knee osteoarthritis (OA) and $6(12 \%)$ patients diagnosed as adolescent tibia vara (TV) with residual varus deformity without arthritic changes, right side was operated upon in $37(74 \%)$ patients while the left side in 13 (26\%) patients with a minimum follow up of 6 months (Table 1). The preoperative exclusion criteria were patients older than 60 years, symptomatic osteoarthritis in the lateral or patellofemoral compartments, osteoporosis, varus deformity $>15^{\circ}$, flexion contracture $>10^{\circ}$, range of motion $<90^{\circ}$, and the presence of severe osteoarthritis in the medial compartment (defined as a grade of 4 on the Kellgren-Lawrence radiographic grading scale) [11]. Written consent was obtained from all patients before surgery with no extra cost offered due to using extra screw fixation.

Table 1: Demographic characteristics of included patients $(N=50)$.

\begin{tabular}{|c|c|}
\hline Parameters & \\
\hline Gender & $18(36 \%)$ \\
\hline Male & $32(64 \%)$ \\
\hline Female & $48.5 \pm 7.4$ \\
\hline Age, $y$ & $37(74 \%)$ \\
\hline Mean \pm SD & $13(26 \%)$ \\
\hline Side & $44(88 \%)$ \\
\hline Rt & $6(12 \%)$ \\
\hline Liagnosis & \\
\hline Osteoarthritis & \\
\hline Tibia vara & \\
\hline
\end{tabular}

\section{Operative Procedure}

Preoperative planning was based on standing short AP and lateral views, all procedures were performed by the senior author (OR), all procedures were performed in the same manner without arthroscopy under spinal anesthesia. Surgical technique (Figure 1). Each patient was positioned in a supine position on a radiolucent table with a thigh tourniquet, draping was done up to the level of the tourniquet. A midline incision was made from a point about $3 \mathrm{~cm}$ distal to the medial joint line slightly medial to the tibial tubercle up to the distal pole of the patella, the incision was enlarged either to improve visualization or to ease plate insertion. The superficial medial collateral ligament was subperiosteally released from the proximal tibia, with subperiosteal blunt dissection of the posterior structure from the back of the tibia till we can digitally feel the head of the fibula, under fluoroscopic examination a Kirschner wire was inserted in an oblique direction from the metaphyseal-diaphyseal junction of the medial proximal tibial cortex, which corresponds to a point just above the upper border of the pes anserinus, and directed toward the lateral proximal tibial cortex aiming at the level of the tip of the fibular head (Figure 1A). We started by an ascending cut made behind the tibial tuberosity in the anterior fourth or $1.5 \mathrm{~cm}$ posterior to the anterior rim of the tibial tuberosity, leaving the patellar ligament attached to the distal tibial fragment, then 2 Homman retractors were inserted, one just behind the patellar tendon and the other was inserted between the posterior aspect of the tibia and the dissected medial and posterior structures. The osteotomy was performed beneath the wire using an osteotome while the knee was in a $15^{\circ}$ flexed position (Figure 1B). Osteotomy ended $5 \mathrm{~mm}$ medial to the lateral cortex. The osteotomy was opened gradually using two flat chisels, and the gaps were maintained using a laminar spreader (Figure 1C). The intraoperative mechanical axis was controlled using the cable technique (Figure 1D) [12] while holding the knee in a fully extended position aiming for a mechanical axis passing at the Fujisawa's point (at 30-40\% lateral to the midpoint of the tibial plateau) [13]. 


\section{Orthopedics and Rheumatology Open Access Journal (OROAJ)}

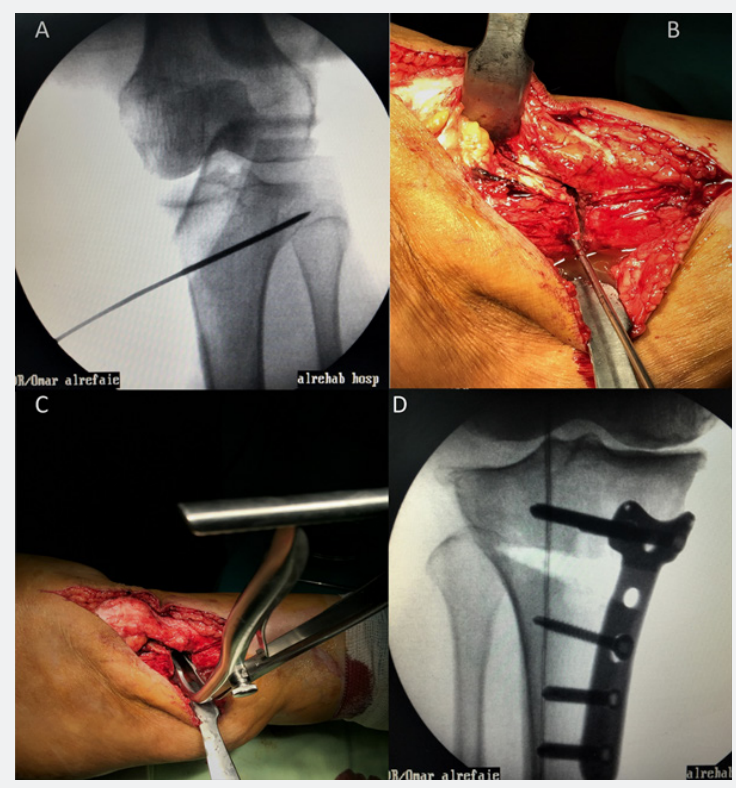

Figure 1: Operative technique,

A. K-wire directed at the fibular head.

B. Biplanar osteotomy was done (tibial osteotomy, osteotomy behind tibial tuberosity).

C. Osteotomy maintained using a laminar spreader.

D. Plate fixation and alignment recheck using cable technique.

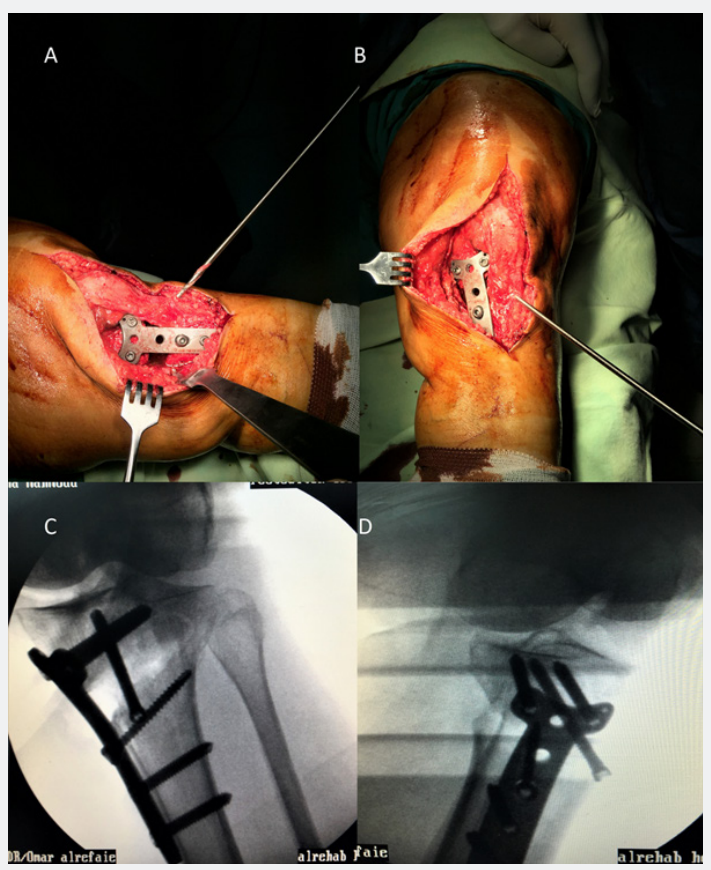

Figure 2: Extra-focal screw fixation technique,

A, B: The direction of the drill going from distal to proximal starting just lateral to the tibial tuberosity aiming at the medial tibial plateau.

C, D: intra-operative Fluoroscopic images showing the optimum position of the screw and its passage between the proximal 2 screws in the lateral view 
For all patients, osteotomy fixation was done using T locked titanium plate (Orthomed-E), with fixation by the non-locked screw done first at the oval hole below osteotomy level to make sure that the plate is resting on the bone in a good position, then formal fixation of the remaining locked screws after confirming plate position under fluoroscopy, proximal part of the plate has three locking holes for fixation in the metaphyseal area, only the 2 peripheral screws are used leaving the middle screw hole empty to accommodate for the passage of the extra-focal screw (Figure $2 \mathrm{~A}$ ), no graft was used, but after secure fixation, with the use of a small curette, some cancellous bone is curetted from the proximal tibia through the osteotomy and left inside the osteotomy site as a local bone graft. Extra-focal screw fixation technique (Figure 2) After confirming the proper limb alignment and plate position, the same drill used for the locking screws $(4.1 \mathrm{~mm})$ is used to drill the track for this screw, we aim at a direction going from distal to proximal, starting at the level of the lateral aspect of the tibial tuberosity targeting the subchondral bone of the medial tibial condyle (Figure 2A \& 2B), the screw should pass between the two proximal screws, caution should be paid not to penetrate the medial tibial plateau by the drill pit, also any resistance felt maybe due to drill hitting either of the screws and the direction should slightly be changed, after confirming the proper position of the drill and measuring the appropriate length, a cortical screw (5 $\mathrm{mm}$ ) from the locking screw set is used with the benefit of wider caliber than the usual cortical $4.5 \mathrm{~mm}$ screws, which theoretically should be stiffer, and the advantage of having threads in the head portion which is designed to lock in the hole of the plate, which may have some purchase in the outer cortical bone at the entry point and we hypothesized that this criterion of the screw may prevent its sinking into the cortex or its backing out which may cause irritation due to subcutaneous nature of this area, care should be taken to make sure that the head of the screw is not prominent from the bone, after inserting the proper screw, the proximal construct should be formed of two screws locked to the plate and another crossing screw from the opposite side taken extra-focally from outside the plate (Figure 2C \& 2D).

Wound closed in layers and no suction drain with the application of a compressive dressing. Post-operative protocol: Isometric quadriceps exercises, active ankle pumping, and straight leg-raising exercises were started on day one postoperative. The compressive dressing was removed on the second day after surgery. Each patient could move the knee as much as tolerated and walk with partial weight-bearing for the first 6 weeks postoperative (as tolerated) except for heavy patients which we advised to just toe-touch weight-bearing protocol. Postoperative radiographic assessment (day 1, 6 weeks, 12 weeks and last follow up at 24 weeks) using a digitalized standing knee AP view (whenever possible). Full weight-bearing was permitted beginning after 6 weeks if the follow-up radiographs show good healing at the osteotomy site.

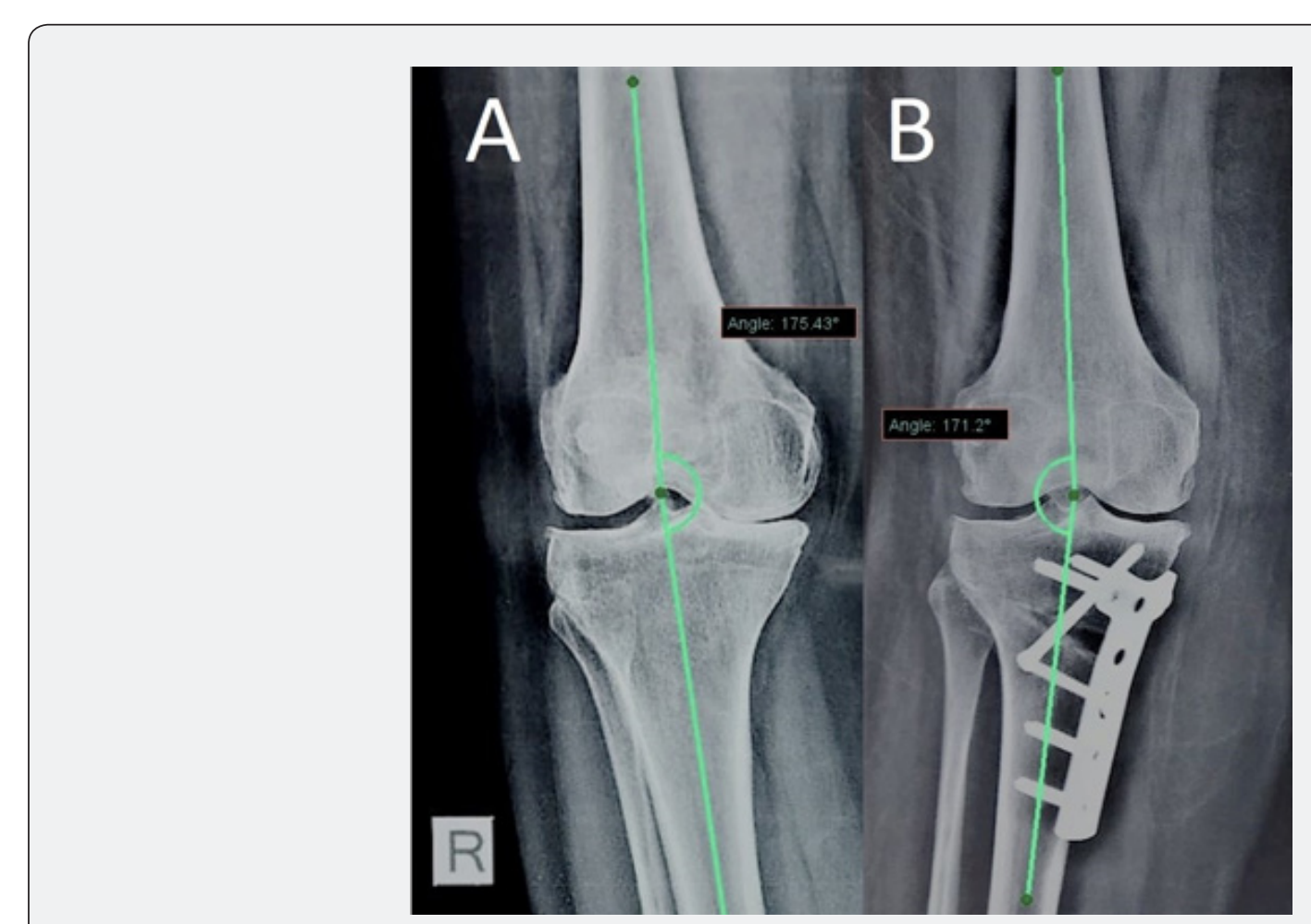

Figure 3: Anatomical tibiofemoral (TF) angle, (AP knee radiograph, A: preoperative - B: postoperative) 


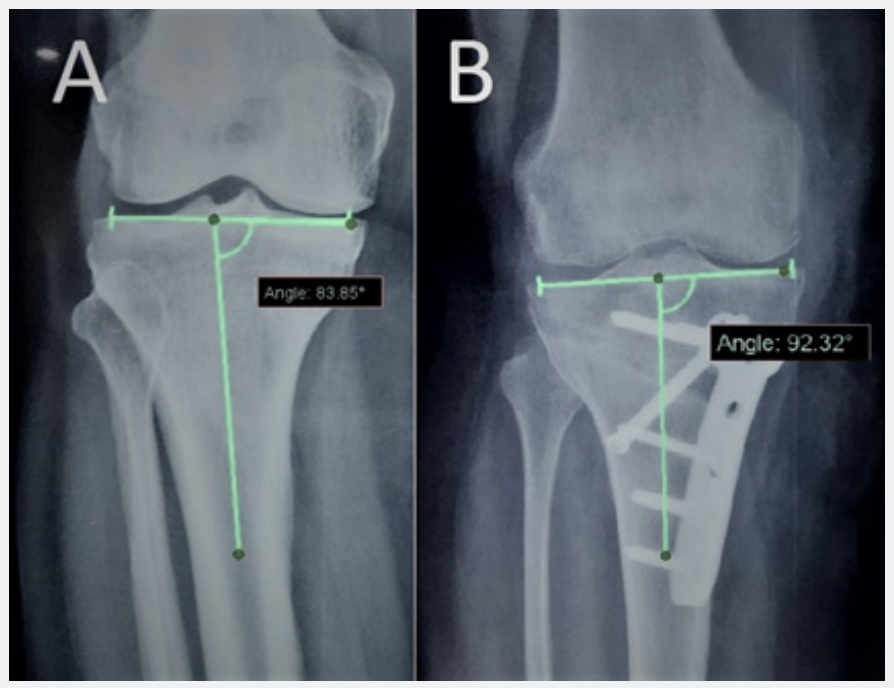

Figure 4: Medial proximal tibial angle (MPTA), (AP knee radiograph, A: preoperative - B: postoperative)

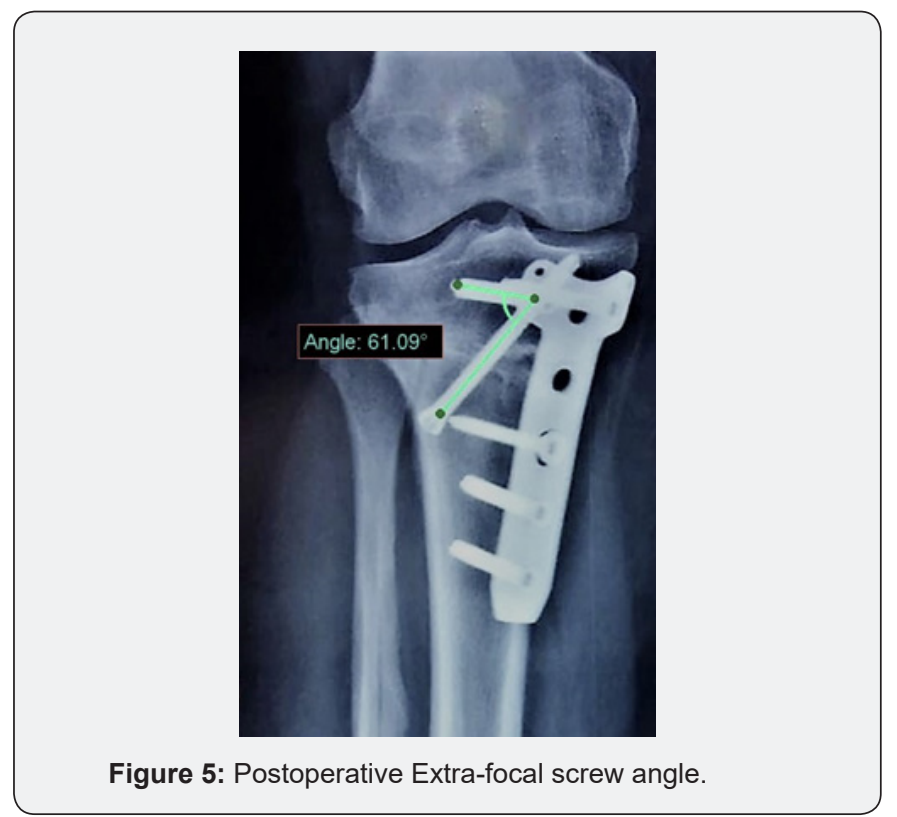

Patient assessment was done as follows: Clinical assessment of knee range of motion and maximum flexion using a handheld goniometer preoperative and at the last follow up visit. Radiographic assessment of the pre and post-operative radiographs as follows: [1] Anatomical tibiofemoral angle (Figure 3) was measured in all cases as the medial angle between the anatomical axis of the tibia and the anatomical axis of the femur with a 7 degrees of valgus to be considered as neutral alignment (added to $180^{\circ}$ to ease calculations) with an angle greater than $187^{\circ}$ considered as valgus and lower than $187^{\circ}$ considered as varus anatomical alignment [2], Medial proximal tibial angle (MPTA) (Figure 4) as the medial angle between the tibia anatomical axis and the proximal tibia joint line, [3] Extra-focal screw angle in relation to the proximal fixation screws (Figure 5) was measured on the postoperative radiographs as the angle originates at the crossing of the screws. The time required for osteotomy site union was assessed according to Apley and Solomon's criteria [14] in weeks, complete bone union according to these criteria defined as the time at which there is no pain upon local palpation, no swelling in the limb, an ability to walk without support and painfree, and evidence of a radiographic bridging callus or trabecula between fragments. If the union was not observed till the 3rd follow up visit at 12 weeks it was considered as a delayed union, and non-unions were diagnosed when trabecular discontinuity was still observed at the last follow up visit at 24 weeks after surgery. Any complications related to the surgery or anesthesia were also reported. Description of means and standard deviation for quantitative variables and frequencies and percentage for qualitative variables were calculated by using SPSS version 22. A comparison of preoperative and postoperative data was performed using the t-test. P-value $<0.05$ will be considered to declare statistical significance.

\section{Results}

Knee range of motion was not significantly changed (P-value $>0.05)$. Mean preoperative range of motion was $115^{\circ}\left(\mathrm{SD} ; 6^{\circ}\right)$ and the mean postoperative range of motion was $112^{\circ}\left(\mathrm{SD} ; 7^{\circ}\right)$. The anatomical TF angle improved significantly from a preoperative mean angle of $177.1^{\circ} \pm 2.4$ (29 patients [58\%] had a deformity equals or more than $10^{\circ}$ varus) to a postoperative mean of $187.5^{\circ} \pm 2.1(\mathrm{p}<0.01)$, the aim in patients diagnosed with medial $\mathrm{OA}$ is to obtain a slight valgus axis to prevent recurring of varus (nearly $8-10^{\circ}$ of valgus in the anatomical axis) which was achieved in $86 \%$ of the arthritic cases with four (9\%) cases were undercorrected and two (5\%) cases were over-corrected, while in 
TV cases we aimed at neutral anatomical correction which was achieved in all cases. The MPTA improved significantly from a preoperative mean of $83.5^{\circ} \pm 3.5$ to a postoperative mean of $94.2^{\circ} \pm 2(\mathrm{p}<0.01)$, the mean inclination of the extra-focal screw in relation to the proximal screws was $65.2^{\circ} \pm 7.5$, the mean time to get radiographic union was $7.9 \pm 2.8$ weeks and the mean time to get full weight-bearing was $8.9 \pm 3.5$ weeks (Table 2). Regarding the complications, we had one $(2 \%)$ case of intraoperative lateral tibial plateau breakage which was only noticed in the immediate postoperative radiographs, and it was in place and treated conservatively, three $(6 \%)$ male patients with delayed union with complete union of the osteotomy site at the last follow up after cessation of smoking, two (4\%) cases had superficial wound infection treated conservatively with daily dressing without the need for surgical intervention, we didn't have any complications related to the implants like breakage or loss of fixation, no irritation from the plate or from the extra-focal screw entry site, no deep wound infections, vascular injuries, or incidents of clinically detected deep vein thrombosis were reported.

Table 2: Comparison between preoperative and postoperative measurements $(\mathrm{N}=50)$.

\begin{tabular}{|c|c|c|c|}
\hline Parameters & Preoperative ${ }^{\dagger}$ & Postoperative $^{\dagger}$ & P value $^{*}$ \\
\hline Range of Motion & $115^{\circ} \pm 6$ & $112^{\circ} \pm 7$ & 0.134 \\
\hline Anatomical TF ${ }^{1}$ angle & $177.1^{\circ} \pm 2.4$ & $187.5^{\circ} \pm 2.1$ & 0 \\
\hline MPTA $^{2}$ & $83.5^{\circ} \pm 3.5$ & $94.2^{\circ} \pm 2$ & 0 \\
\hline \multicolumn{2}{|c|}{} \\
\hline \multicolumn{2}{|c|}{${ }^{1}$ TF: tibiofemoral; ${ }^{2}$ MPTA: medial proximal tibial angle } \\
\hline ${ }^{+}$Data are presented as mean \pm standard deviation \\
\hline
\end{tabular}

\section{Discussion}

Performing MWOHTO in treating knee osteoarthritis had gone down over the last 3 decades as it had been considered technically demanding, however, it had been shown in recent studies that sport activities even if demanding can be maintained after this procedure [15]. The main aim of performing MWOHTO is to accurately correct limb alignment which should be maintained by rigid fixation till osteotomy fully unite [16]. We believe that these goals could be achieved after utilizing this new technique of adding extra fixation in another plane through the extra-focal screw. Both biological and mechanical factors should be taken into consideration if the surgeon aims at an optimum MWOHTO outcome, lateral cortex continuity in association with robust fixation and soft tissue integrity is among these factors $[1,17]$. Although MWOHTO is considered as a simple procedure, intraoperative as well as postoperative complications can occur, most of these complications caused mainly by surgical and technical errors, of these are: under or overcorrection, breakage of the lateral cortex, delayed and non-union [18].

In comparison to our study where we had $24 \%$ minor complications, Lee et al. [4] in their study identified $29.3 \%$ complication rate after MWOHTO for varus osteoarthritis of the knee, most of these were minor complications which needed no surgical intervention as lateral cortex fracture, delayed union and skin irritation from the plate, on the contrary to our study they had 3 major complications which needed surgical intervention one of them is due to non-union. The inherent instability of the MWOHTO is due to the gap created in the proximal tibia, attention should be paid for fixation and integrity of the lateral cortex to prevent early failure with loos of correction [19]. We didn't encounter any cases of non-union in our series while Meidinger et al. [20] after having 5.4\% non-union in their series concluded that the intact lateral cortex with strong fixation was essential for the prevention of such complications. The use of locking compression plates or extra screws, as was utilized in our series, had been recommended when the correction angle is large and a long wedge height will occur for the fear of breaking the lateral cortex or even a tibial plateau fracture which will affect osteotomy stability [4].

In comparison to our series where we didn't report any complications related to using a $\mathrm{T}$ locked plate which is considered as a fixed angle device, Puddu plate usage had been reported to be associated with a complication rate ranging from 37.7 to $55 \%$, while less complication rate was reported with LCP and non-locking T-plates ranging from 1.9 to $8.6 \%[1,21,22]$, in another study by Chaturong et al. [23] where they reported a low complication rate with both the use of T-buttress plates $(6.7 \%)$ and the TomoFix technique (10\%). No iliac bone graft or a bone graft substitute was used in this series, a meta-analysis done by Jae et al. [24] showed that similar radiological union and correction preservation after MWOHTO regardless of tibial bone quality, also they stated that the currently available evidence can't support the superiority of using bone graft over without.

We had been able to obtain good clinical and radiological results compared to previously reported studies with no complications related to utilizing this new technique [25-27]. 


\section{Limitations of the Study}

Lack of a biomechanical study to support our hypothesis that adding this screw will increase the axial and rotational stability of the construct, also we didn't compare the results with a matching group of patients done without adding an extra-focal screw, also we didn't report the full clinical outcomes regarding knee function.

\section{Conclusion}

We believe from the clinical and radiological results of our series that "Biplanar fixation by adding an extra fixation by the extra-focal screw" leads to more axial and torsional stability to osteotomy fixation construct with the subsequent full union and early recovery, but the further biomechanical study is strongly recommended.

\section{References}

1. Coventry MB, Ilstrup DM, Wallrichs SL (1993) Proximal tibial osteotomy. A critical long-term study of eighty-seven cases. J Bone Joint Surg Am 75(2): 196-201.

2. Jackson JP, Waugh W, Green JP (1969) High tibial osteotomy for osteoarthritis of the knee. J Bone Joint Surg Br 51(1): 88-94.

3. Insall JN, Joseph DM, Msika C (1984) High tibial osteotomy for varus gonarthrosis. A long-term follow-up study. J Bone Joint Surg Am 66(7): 1040-1048.

4. Lee DC, Byun SJ (2012) High tibial osteotomy. Knee Surg Relat Res 24(2): 61-69.

5. Chae DJ, Shetty GM, Wang KH, Montalban AS Jr, Kim JI, et al. (2011) Early complications of medial opening wedge high tibial osteotomy using autologous tricortical iliac bone graft and T-plate fixation. Knee 18(4): 278-284.

6. Valkering KP, van den Bekerom MP, Kappelhoff FM, Albers GH (2009) Complications after tomofix medial opening wedge high tibial osteotomy. J Knee Surg 22(3): 218-225.

7. Matthews LS, Goldstein SA, Malvitz TA, Katz BP, Kaufer H (1988) Proximal tibial osteotomy. Factors that influence the duration of satisfactory function. Clin Orthop Relat Res 229: 193-200.

8. Miller BS, Downie B, McDonough EB, Wojtys EM (2009) Complications after medial opening wedge high tibial osteotomy. Arthroscopy 25(6): 639-646.

9. Warden SJ, Morris HG, Crossley KM, Brukner PD, Bennell KL (2005) Delayed- and non-union following opening wedge high tibial osteotomy: surgeons' results from 182 completed cases. Knee Surg Sports Traumatol Arthrosc 13(1): 34-37.

10. Seo SS, Kim OG, Seo JH, Kim DH, Kim YG, et al. (2016) Complications and Short-Term Outcomes of Medial Opening Wedge High Tibial Osteotomy Using a Locking Plate for Medial Osteoarthritis of the Knee. Knee Surg Relat Res 28(4): 289-296.

11. Kelgren G, Jeffrey M, Ball J (1963) Atlas of standard radiographs. Oxford, Blackwell scientific, UK.
12. Krettek C, Miclau T, Gru O, Schandelmaier P, Tscherne H (1998) Intraoperative control of axes, rotation and length in femoral and tibial fractures technical note. Injury 29: 29-39.

13. Fujisawa Y, Masuhara K, Shiomi S (1979) The effect of high tibial osteotomy on osteoarthritis of the knee. An arthroscopic study of 54 knee joints. Orthop Clin North Am 10(3): 585-608.

14. Solomon L, Warwick D, Nayagam S (2010) Apley's system of orthopaedics and fractures. CRC press, USA.

15. Smith J, Wilson A, Thomas N (2013) Osteotomy around the knee: evolution, principles and results. Knee Surgery, Sports Traumatology, Arthroscopy 21(1): 3-22.

16. Sabzevari S, Ebrahimpour A, Roudi MK, Kachooei AR (2016) High tibial osteotomy: a systematic review and current concept. Archives of Bone and Joint Surgery 4(3): 204.

17. Rose T, Imhoff $A B$ (2007) Complications after transgenicular osteotomies. Operative Techniques in Orthopaedics 17(1): 80-86.

18. Song SJ, Bae DK, Kim KI, Lee CH (2016) Conversion Total Knee Arthroplasty after Failed High Tibial Osteotomy. Knee Surg Relat Res 28(2): 89-98.

19. Jackson J, Waugh W (1961) Tibial osteotomy for osteoarthritis of the knee. J Bone Joint Surg Br 43(4): 746-751.

20. Meidinger G, Imhoff AB, Paul J, Kirchhoff C, Sauerschnig M, et al. (2011) May smokers and overweight patients be treated with a medial openwedge HTO? Risk factors for non-union. Knee Surg Sports Traumatol Arthrosc 19(3): 333-339.

21. van den Bekerom MP, Patt TW, Kleinhout MY, van der Vis HM, Albers GH (2008) Early complications after high tibial osteotomy: a comparison of two techniques. J Knee Surg 21(1): 68-74.

22. Kolb W, Guhlmann H, Windisch C, Kolb K, Koller H, et al. (2009) Opening-wedge high tibial osteotomy with a locked low-profile plate. J Bone Joint Surg Am 91(11): 2581-2588.

23. Pornrattanamaneewong C, Numkanisorn S, Chareancholvanich $\mathrm{K}$ Harnroongroj T (2012) A retrospective analysis of medial opening wedge high tibial osteotomy for varus osteoarthritic knee. Indian journal of orthopaedics 46(4): 455.

24. Han JH, Kim HJ, Song JG, Yang JH, Bhandare NN, et al. (2015) Is Bone Grafting Necessary in Opening Wedge High Tibial Osteotomy? A MetaAnalysis of Radiological Outcomes. Knee Surg Relat Res 27(4): 207220.

25. Niemeyer P, Schmal H, Hauschild O, von Heyden J, Südkamp NP, et al. (2010) Open-wedge osteotomy using an internal plate fixator in patients with medial-compartment gonarthritis and varus malalignment: 3-year results with regard to preoperative arthroscopic and radiographic findings. Arthroscopy: The Journal of Arthroscopic \& Related Surgery 26(12): 1607-1616.

26. Staubli AE, De Simoni C, Babst R, Lobenhoffer P (2003) TomoFix: a new LCP-concept for open wedge osteotomy of the medial proximal tibiaearly results in 92 cases. Injury 34(2): 55-62.

27. Naudie D, Bourne RB, Rorabeck CH, Bourne TJ (1999) The Install Award. Survivorship of the high tibial valgus osteotomy. A 10-to-22year followup study. Clin Orthop Relat Res 1999(367): 18-27. 
This work is licensed under Creative Commons Attribution 4.0 License DOI: 10.19080/OROAJ.2020.15.555922
Your next submission with Juniper Publishers will reach you the below assets

- Quality Editorial service

- Swift Peer Review

- Reprints availability

- E-prints Service

- Manuscript Podcast for convenient understanding

- Global attainment for your research

- Manuscript accessibility in different formats ( Pdf, E-pub, Full Text, Audio)

- Unceasing customer service

Track the below URL for one-step submission https://juniperpublishers.com/online-submission.php 